\title{
Urban lizards use sleep sites that mirror the structural, thermal, and light properties of natural sites
}

\author{
Nitya Prakash Mohanty ${ }^{1}$ (i) $\cdot$ Mihir Joshi $^{1}$ (i) $\cdot$ Maria Thaker $^{1}$ (i)
}

Received: 3 August 2021 / Revised: 6 November 2021 / Accepted: 9 November 2021 / Published online: 3 December 2021

(c) The Author(s), under exclusive licence to Springer-Verlag GmbH Germany, part of Springer Nature 2021

\begin{abstract}
Global change processes such as urbanization are likely to affect sleep behavior, by altering abiotic (e.g., thermal and illumination) and biotic conditions (e.g., predation pressure) that influence sleep. However, little is known of how sleep behavior responds to urbanization and whether this response is flexible or conserved across populations. We quantified sleep site characteristics of the peninsular rock agama Psammophilus dorsalis in Bangalore city and surrounding rural areas. We find that $P$. dorsalis in urban areas display remarkable behavioral flexibility in response to the novel stressor of artificial light at night, being nine times more likely to use covered sleep sites that limit illumination, compared to lizards in rural areas. However, sleep sites in both populations were highly conserved in terms of substrate type (i.e., rocky with high surface rugosity) and their thermal properties. Our findings support behavioral amelioration of potentially adverse effects of night light in urban areas, even within the restricted availability of preferred substrates as sleep sites. Our study is one of the first to comprehensively compare sleep behavior in rural and urban areas and demonstrate substantial behavioral flexibility. The role of sleep behavior in the coping strategies of animals to urbanization needs further research attention.
\end{abstract}

\section{Significance statement}

Sleep is essential to animal life, yet it imposes certain costs such as making sleeping individuals vulnerable to predators. "Where" an animal sleeps (or its sleep site) is therefore important to ensure safety from predators but also to provide conducive environmental conditions. Cities can transform the availability of ideal sleep sites and can alter their thermal properties, in addition to being intensely illuminated by night light that hampers sleep. In this study, we compared sleep site characteristics of rural and urban populations of the peninsular rock agama Psammophilus dorsalis. We find that urban lizards sleep in sheltered sleep sites that shield them from night light but are highly dependent on rough, rocky substrates in both the city and rural areas. The remarkable flexibility in sleep behavior displayed by urban lizards is likely to help them cope in a city.

Keywords Sleep ecology $\cdot$ Urbanization · Artificial light at night $\cdot$ ALAN $\cdot$ Light pollution · Thermography

\section{Introduction}

Communicated by C. R Gabor.

This article is a contribution to the Topical Collection Using behavioral ecology to explore adaptive responses to anthropogenic change - Guest Editors: Jan Lindström,Constantino Macias Garcia, Caitlin Gabor

Nitya Prakash Mohanty

nitya.mohanty@gmail.com

1 Centre for Ecological Sciences, Indian Institute of Science, Bangalore, India 560012
Animals spend a substantial portion of their day sleeping, during which, multiple essential functions, from removal of metabolic waste from the brain and energy allocation, to neural reorganization and memory consolidation, are served (Schmidt 2014). Sleep in the wild, however, can also incur substantial costs, especially in terms of increased vulnerability to predators and reduced opportunities to acquire resources (e.g., suitable thermal conditions) (Eban-Rothschild et al. 2017). Therefore, ecological processes are likely to shape sleep behavior and its associated traits, to minimize the costs of sleep (Anderson 1984; Lima et al. 2005). For example, characteristics of sleep sites in the wild are often 
specialized with respect to their structure and microclimate to provide suitable thermo-hydric conditions and safety from predators (Anderson 1998; Mohanty et al. 2021). Apart from sleep sites, a suite of sleep traits pertaining to physiology (e.g., sleep duration), morphology (e.g., color during sleep), and behavior (e.g., sleep posture), as well as inter-individual interactions (e.g., conspecific aggregations), constitute the sleep ecology of a species (Mohanty et al. 2021). However, the ecology of sleep remains understudied in most taxa, and even more so in the context of global change processes, such as urbanization.

Urbanization is likely to affect sleep behavior in animals, as urban areas have altered abiotic and biotic conditions that are known to influence sleep. Compared to undisturbed areas, animals in urban areas experience different substrate types, increased substrate temperature (i.e., the urban heat island effect; Arnfield 2003), and novel stressors such as artificial light at night (ALAN) and noise (Warren et al. 2006; Nordt and Klenke 2013). The composition of predators (e.g., feral cats and dogs) and competitors in urban areas is also likely to be different (Fischer et al. 2012). All these anthropogenic changes to environments can alter various aspects of sleep ecology. For example, high temperatures at sleep sites, a likely consequence of urbanization, can render the sites unusable (Vasconcelos et al. 2012) or hamper sleep duration (Downs et al. 2015). Similarly, under perceived risk of predation in unsafe sleep sites, sleep intensity can be reduced (Tisdale et al. 2018). Some aspects of urbanization, such as ALAN, can be more pervasive. ALAN, comprising both amber and white light in cities, is known to alter circadian rhythms (e.g., Secondi et al. 2021) and is considered to be especially detrimental to the sleep of diurnally active animals (Aulsebrook et al. 2018, 2020). The effect of ALAN on sleep has been better studied in birds (Aulsebrook et al. 2021), where studies have found evidence for its effect on sleep duration (Raap et al. 2015; Ouyang et al. 2017; Sun et al. 2017), composition (Aulsebrook et al. 2020), and timing (Dominoni et al. 2014). Animals can, however, mitigate the costs of ALAN by avoiding illuminated sleep sites (Aulsebrook et al. 2018; Raap et al. 2018a). When suitable sleep sites are limited, sleep site selection in urban areas can be constrained at multiple spatial scales (e.g., sleep sites of the Powerful owl Ninox strenua; Bradsworth et al. 2021). Regardless of the drivers, disruption of sleep can have negative downstream effects on the health or immune function of animals (Imeri and Opp 2009).

Our understanding of how sleep behavior is affected by urbanization has several knowledge gaps. Firstly, response of sleep to factors associated with urbanization has been limitedly studied in wild populations and rarely in reptiles (Mohanty et al. 2021). This assumes further importance as sleep in reptiles is perhaps more sensitive to ALAN than in birds and mammals, due to the presence of a light-sensitive pineal eye in this group of vertebrates (Mohanty et al. 2021). Secondly, there is a lack of comprehensive, systematic studies on urban sleep sites, especially with respect to their structural, thermal, and light conditions. Finally, the effect of behavioral decisions in ameliorating potential adverse effects of urbanization on sleep is not well understood. As a corollary, whether sleep traits such as the selection of sleep sites remain conserved despite environmental variation (Bors et al. 2020) or are indeed flexible in response to novel environments (Aulsebrook et al. 2018) needs to be determined.

The peninsular rock agama Psammophilus dorsalis (Gray 1831) is a diurnally active agamid lizard that occurs in rocky, arid regions of peninsular India (Radder et al. 2005). Adults of the species are medium-sized (SVL $\sim 65$ to $150 \mathrm{~mm}$ ) and display sexual dimorphism; males have larger body size and head width and show conspicuous physiological colors during the breeding season (Radder et al. 2006; Batabyal and Thaker 2017). Urban populations of $P$. dorsalis in Bangalore city and rural populations outside the city have been well studied in a comparative framework, presenting a model system to understand behavioral responses to urbanization. $P$. dorsalis populations in urban settings are known to be less risk averse (shorter flight initiation distances; Batabyal et al. 2017), demonstrate faster learning and relearning skills with respect to refuge selection (Batabyal and Thaker 2019a), show higher circulating corticosterone levels, a physiological measure of stress, but are similar in most other health indicators (Amdekar et al. 2018; Batabyal and Thaker 2019b). Although behavioral responses of $P$. dorsalis during the activity phase have been well documented, there is a complete lack of knowledge on its sleep behavior and the response of sleep to urbanization.

In this study, we aim to evaluate the response of sleep behavior in Psammophilus dorsalis to urbanization-associated alteration of the physical environment. In particular, we determine the ways in which the structural, thermal, and light environments of sleep sites differ between urban and rural habitats. We hypothesize that $P$. dorsalis will use sleep sites in urban environments that closely match the structural, thermal, and light conditions of its sleep sites in rural habitats. Specifically, we predict that $P$. dorsalis will show increased use of crevices and covered sites in urban areas, which would reduce the overall lux values at sleep sites to match those in rural habitats. We also predict that regardless of the possible environmental differences between urban and rural habitats, the structural characteristics and thermal conditions of sleep sites would be similar at urban and rural sites. Such use of sleep sites would indicate that lizards are actively altering their behavior in urban areas. 


\section{Methods}

We conducted the study in three urban and three rural sites in and outside Bengaluru city (Fig. 1). Rural study sites were ca. $70 \mathrm{~km}$ away from the urban sites; all sites within urban and rural areas were at least $1 \mathrm{~km}$ apart. Urban sites were characterized by residential areas interspersed with empty plots, with some gardens and unmanaged scrub vegetation. Notably, most houses and plots were fenced by concrete walls, which provide coarse substrate (when unplastered/ unpainted) and vertical crevices at systematic distances. Other artificial substrates (e.g., metal sheets, brick piles) were found near construction sites in many of the undeveloped plots. Urban sites were illuminated with both amber and white light from street lamps. In contrast, rural sites comprised rocky outcrops and boulders interspersed with scrub vegetation (including the invasive Lantana camara) and were mostly undisturbed with minimal human intrusions (e.g., cattle grazing, human-made trails, rock climbing). Artificial illumination was absent at rural sites.

We conducted the study in September and October 2020, towards the end of the breeding season for $P$. dorsalis. As there was no prior information on sleep sites, we conducted a pilot study in August 2020 to determine the sampling time and method. Based on preliminary findings from the pilot study, we carried out nocturnal sampling between 1900 and $2330 \mathrm{~h}$ on 17 occasions. Given that our survey period was relatively short and survey nights were not clustered by urban and rural areas, we did not expect sampling conditions to differ between urban and rural sites in terms of moonlight, ambient temperature, or wind speed. We did not, however, measure cloud cover, although it can regulate environmental luminosity by interacting with ALAN or moonlight (van Hasselt et al. 2021). Surveys were constrained to $3 \mathrm{~h}$ on most occasions to avoid fatigue in detection (Lardner et al. 2019), and survey trails at each site were at least $100 \mathrm{~m}$ apart. Typically, three personnel conducted the sampling and scanned all substrates (from ground level up to $4 \mathrm{~m}$ ) with headlamps (Ledlenser MH6). We searched for lizards using white lights but switched to red lights immediately upon spotting an individual to avoid disturbance. Observed individuals were considered to be sleeping as they displayed behavioral criteria for sleep, including a typical sleep posture (with eyes closed, head and body prone on the substrate), behavioral quiescence, increased arousal threshold (e.g., lizards did not escape upon approach as they would during the diurnal active period and only initiated escape when disturbed by white light or rapid motion causing

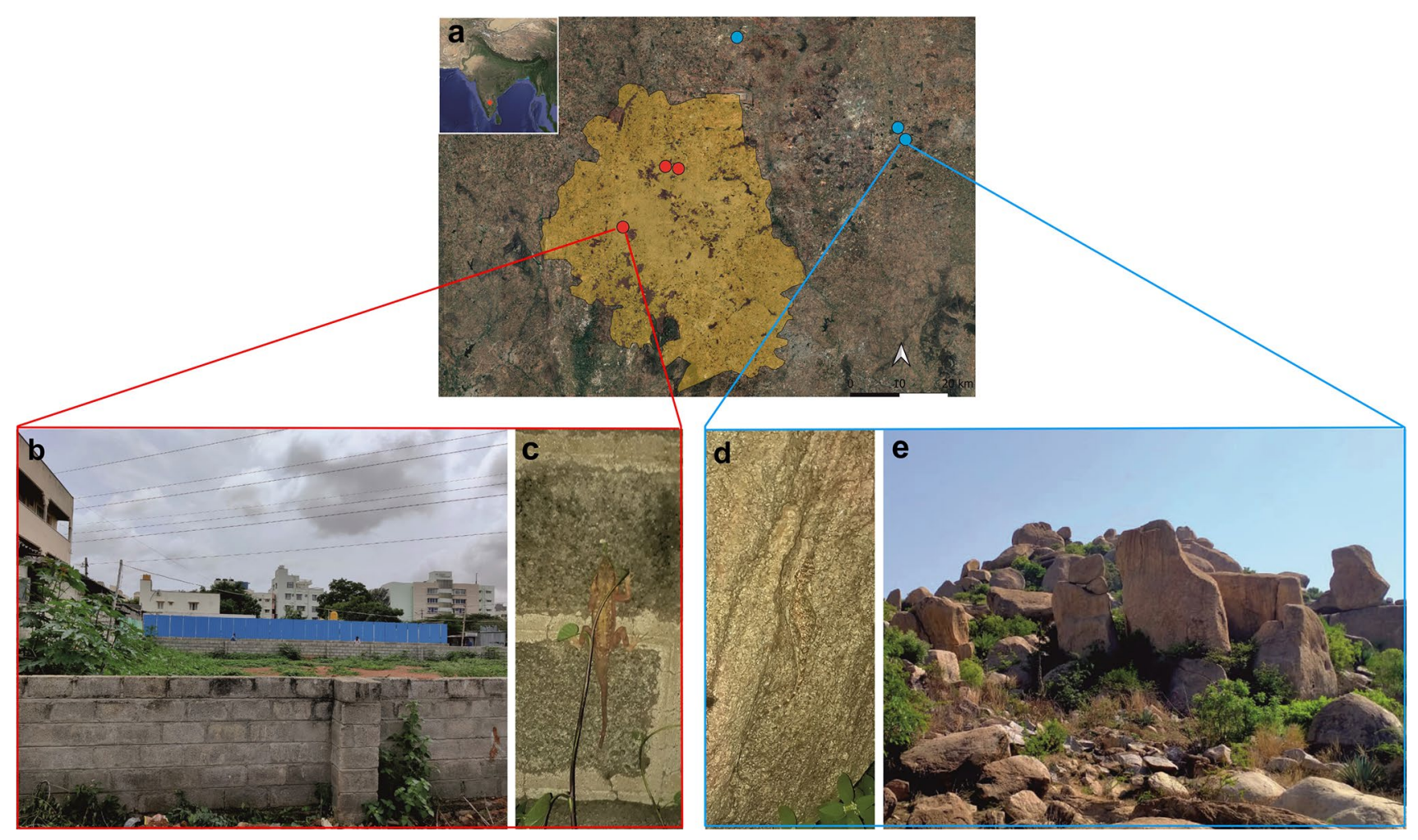

Fig. 1 a Urban (red circles) and rural (blue circles) field sites sampled for sleeping Psammophilus dorsalis in Bangalore, India (inset Fig.). Bangalore urban district is shaded to mark the urban limits.
Typical habitats of $\mathbf{b}$ urban and e rural sites. $\mathbf{c}$ An adult male sleeping on a concrete wall in an urban site. $\mathbf{d}$ An adult female sleeping on a rock in a rural site 
vibration), and reversibility to wakefulness upon sufficient stimulation (Piéron 1912).

We quantified sleep sites with respect to their structural, thermal, and light characteristics. The structure of the sleep sites was recorded in terms of substrate type (e.g., rock, unpolished wall, vegetation), perch height (measured in $\mathrm{cm}$ to ground level), perch orientation (i.e., orientation of the perch with respect to the ground-horizontal, angular, vertical; Bors et al. 2020), and perch depth (for only rocky substrates: "exposed," "covered," "crevice"). We defined a "covered" sleep site as a site on a rocky substrate that was covered by vegetation or artificial substrate (e.g., tarpaulin sheet), which was adequate to change the light conditions at the site/hindered detection; an "exposed" site as one without any cover that hindered detection or light; and a "crevice" as any site within rock crevices or in gaps between concrete walls. For sleep sites on vegetation, we followed Mohanty et al. (2016) to measure plant girth (in cm), perch type (e.g., trunk, leaf), perch width (e.g., branch circumference in $\mathrm{cm}$ ), and distance to main trunk (in $\mathrm{cm}$ ). We attempted to minimize any potential bias in detection of individuals (e.g., "covered" vs "exposed"), by searching all sites thoroughly along the survey trails.

Additionally, we measured head direction of the lizard as this may be an important indicator of visual cues available to the lizard upon waking and may influence the decision to or response of escape (Mohanty et al. 2016). We recorded head direction as "inward"/ "outward"/ "angular" for vegetation, defined with respect to a potential approaching predator from the base of the plant (see Mohanty et al. 2016) and "upward"/ "downward"/ "angular" for rocky substrates.

We used a thermal camera (FLIR T640) for thermography of lizard body temperature, perch temperature (adjacent to the lizard), and substrate temperature. To determine if lizards selected specific sleep sites based on thermal properties, we compared the temperature of each sleep substrate to four "unused" (or potentially available) substrates within $1 \mathrm{~m}$ radius of the sleep site (denoted as environment temperature). All thermal images were taken at a focal length of ca. $1.5 \mathrm{~m}$, which enabled us to capture ca. $1 \mathrm{~m} \times 1 \mathrm{~m}$ area. Thermal images were analyzed using FLIR Thermal Studio Pro software. Following Goller et al. (2014), we extracted mean body temperature (along the dorsal line from snout to tail base; Fig. 2a), mean substrate temperature $(1 \mathrm{~m} \times 1 \mathrm{~m}$ area immediately around the lizard; Fig. 2a), and mean environment temperature (mean of the four unused substrates; Fig. 2b). In the case of multiple substrate types in a thermal image, we only considered the one used by the lizard. We modified the measurement of perch temperature (see Goller et al. 2014) to encompass all substrates adjoining the lizard, using three polygons on each side of the body (outer boundary: snout tip-proximal fore digit, joint of humerus and radius-joint of femur and tibia, and joint of tibia and metatarsal-tail base; Fig. 2a). For environmental temperature, we selected the substrate type that accounted for the majority ( $>50 \%$ ) of the focal area in each thermal image.

Light conditions at the sleep site of each individual (Dominoni et al. 2014) was measured using a lux meter (MECO 930P; precision $0.1 \mathrm{~lx}$ ) at the level of the head with respect to the orientation of the lizard (e.g., lux meter was held parallel to the ground, if perch orientation was parallel). Overall, luminosity was recorded to be $01 \mathrm{x}$ in rural environments on the survey nights, although natural illumination due to moonlight can range from 0.01 to $1 \mathrm{~lx}$ (Bennie et al. 2016). We recorded luminosity up to approximately $50 \mathrm{~lx}$ near streetlights in urban areas. After all microhabitat conditions and posture information was recorded, we captured sleeping lizards by hand and measured snout-vent length and total length using a ruler ( $1 \mathrm{~mm}$ precision). Finally, we recorded the age-sex category (male, female, or juvenile); males were easily distinguished from females based on a wider head, well-defined jaw muscles, and larger size (mean SVL \pm SE for male: $12.15 \pm 0.18 \mathrm{~cm}$, female: $8.23 \pm 0.1 \mathrm{~cm}$, juvenile: $4.56 \pm 0.09 \mathrm{~cm}$ ). Lizards were released immediately after measurements at their sleep sites. Data was not recorded blind, as our study involved animals in the wild.

\section{Data analyses}

All response variables were first examined for normality using Shapiro-Wilk's tests and visualized using q-q plots. Perch height was square-root transformed to meet the assumptions of normality. Similarly, the distributions of model residuals were visualized to evaluate if they were normally distributed. Multinomial logistic regressions were computed for sleep site substrate type, perch orientation, and perch depth, with both "population" (urban or rural) and "age" (adult or juvenile) as predictors; we did not include an interaction term between the predictors as we had no a priori expectation for interactions between population and age. Further, the interaction effect was not significant in any of the models and masked the effects of the main predictors (Online Resource 1 Table 1). For significant relationships (at $\alpha=0.05$ ), we exponentiated the partial regression coefficients to generate true odds ratios. For perch height, we performed a general linear model with a Gaussian error distribution, using both population and age as predictors. As "lux" (luminosity) at sleep sites was non-normally distributed, even after transformations, we conducted two nonparametric Wilcoxon rank sum tests with population and age as single predictors. Similarly, we compared luminosity values of "exposed" and "covered" sleep sites with a Wilcoxon rank sum test. We performed all statistical analyses in $\mathrm{R}$ (version 4.0.4; $\mathrm{R}$ Core Team 2021). 
Fig. 2 a Thermal image with measurement markings to calculate mean body temperature (dorsal line from snout to tail base), mean perch temperature (1-6, mean of six polygons adjacent to the body), and mean substrate temperature ( $\mathrm{S}$, excluding the lizard). b Thermal image showing unused substrates within $1 \mathrm{~m}$ from a lizard sleep site. $\mathbf{c}$ Temperature of a sleeping lizard's body, its perch, substrate, and the surrounding environment for Psammophilus dorsalis in urban and rural habitats. Boxes indicate the interquartile range (IQR), with the central line depicting the median and the whiskers extending to $1.5 \times \mathrm{IQR}$, overlaid with data points a)

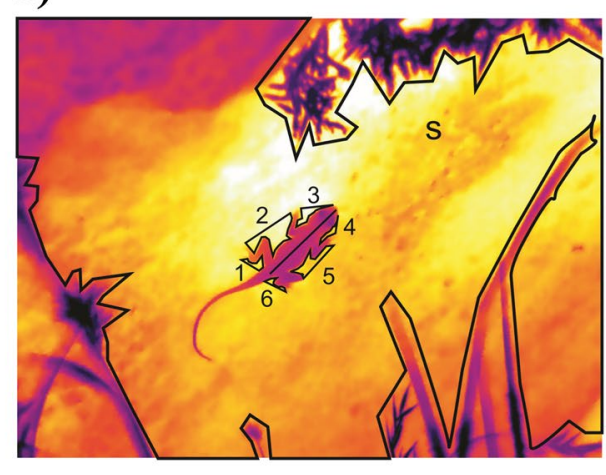

b)

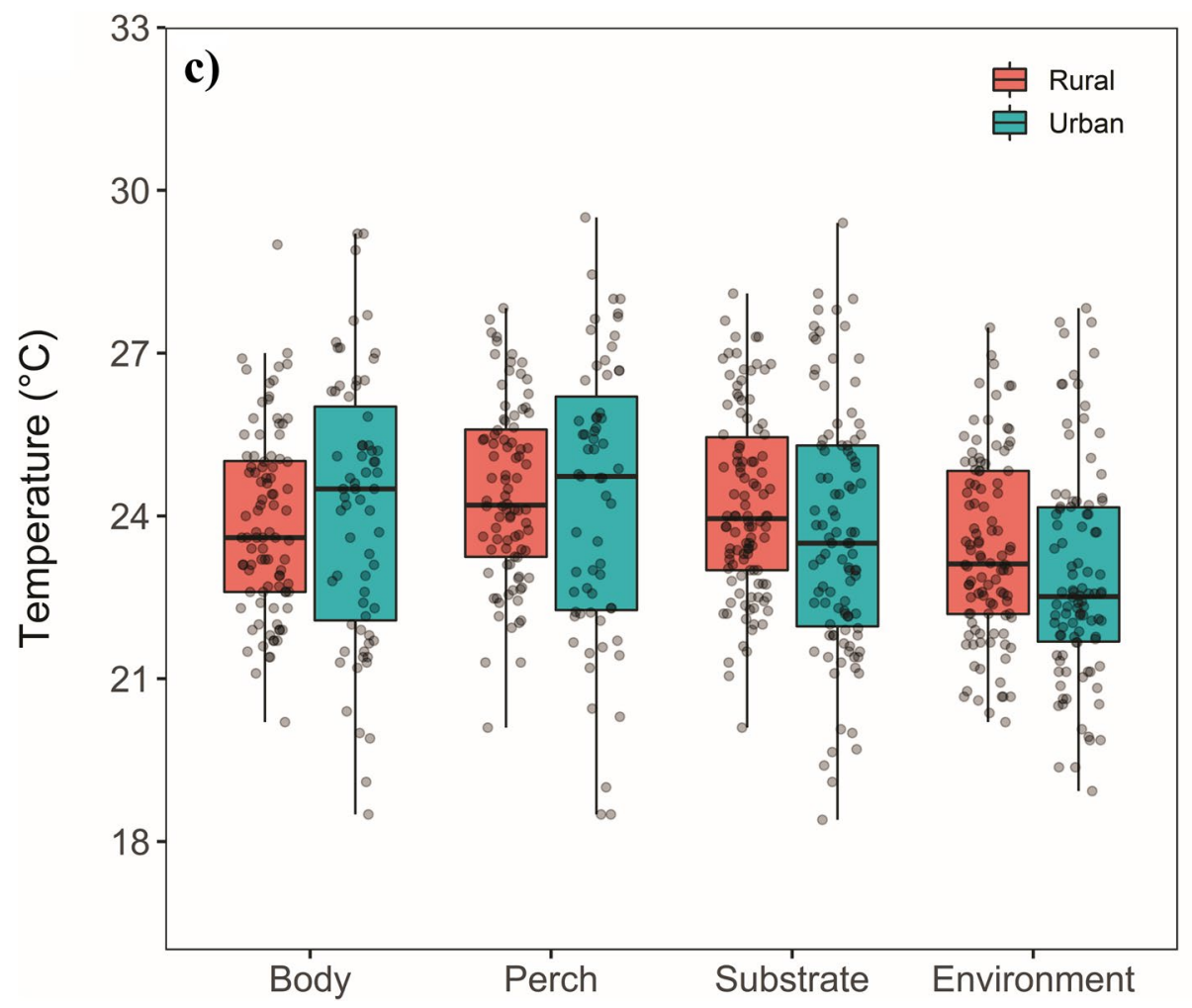

\section{Results}

\section{Structural characteristics}

We observed a total of 302 sleeping lizards, of which $90.73 \%$ were found on rocky substrates (Fig. 3). Urban lizards used unpolished concrete block walls $(87.2 \%$ of lizards in that population), brick piles $(0.61 \%)$, and cement sheets $(0.61 \%)$, whereas rural lizards used rocks/boulders (93.48\%) (Fig. 3). The usage of vegetative substrates as compared to rocky substrates did not differ significantly between urban and rural lizards (Table 1). Irrespective of population, juveniles had a higher likelihood of using vegetative substrates compared to adults (odds ratio $=4.82,95 \% \mathrm{CI}=3.73-5.91$; Table 1 ). Urban lizards had small but significantly lower odds ratios of sleeping on horizontal $(0.41,95 \% \mathrm{CI}=-0.27$ to 1.09$)$ and angular perches $(0.07, \mathrm{CI}=-1.16$ to 1.31$)$ compared to vertical perches, than rural lizards (Table 1). Sleep sites for urban lizards were significantly lower in height (Table 1), with a mean difference of $20.80 \mathrm{~cm}(\mathrm{SE}=6.96)$ with rural lizards.

For individuals on rocky substrates at both urban and rural habitats, head direction was predominantly "upwards" (95.97\%), whereas individuals on vegetative substrates faced "inwards" (51.85\%) and "outwards" (44.44\%) in similar proportions. We observed 47 individuals sleeping in close vicinity to each other on the same substrate (touching or $<60 \mathrm{~cm}$ apart) on 20 occasions (urban: 27 individuals in 11 aggregations, rural: 20 individuals in 9 aggregations). Aggregations comprised of 2-4 lizards clustered together in male-female, male-female-juvenile, female-female, female-juvenile, and all juvenile groups. 
Table 1 The effects of lizard population (rural or urban) and age (adult or juvenile) on the characteristics of sleep sites for Psammophilus dorsalis. For all regressions, reference values of predictors are "rural" and "adult"; untransformed regression coefficients $( \pm$ SE) are reported. Statistically significant $p$-values (at $\alpha=0.05$ ) are in bold. *Non-parametric Wilcoxon rank sum test (Statistic W)

\begin{tabular}{llll}
\hline Model & Response type & \multicolumn{2}{l}{ Comparison } \\
\cline { 3 - 4 } & & Rural-urban & Adult-juvenile \\
\hline Substrate (reference: rocky) & Vegetative & $0.44 \pm 0.43(0.305)$ & $1.57 \pm 0.55(\mathbf{0 . 0 0 4})$ \\
& Ground & $9.81 \pm 128.48(0.939)$ & $-10.70 \pm 179.21(0.952)$ \\
Perch orientation (reference: vertical) & Horizontal & $-0.88 \pm 0.34(\mathbf{0 . 0 1 1})$ & $0.53 \pm 0.35(0.134)$ \\
& Angular & $-2.60 \pm 0.63(<\mathbf{0 . 0 0 1})$ & $0.79 \pm 0.45(0.078)$ \\
Perch depth (reference: exposed) & Covered & $2.22 \pm 0.42(<\mathbf{0 . 0 0 1})$ & $-2.58 \pm 0.42(<\mathbf{0 . 0 0 1})$ \\
Perch height & Crevice & $0.53 \pm 0.71(0.45)$ & $-10.38 \pm 42.09(0.805)$ \\
Lux* & - & $-0.79 \pm 0.33(\mathbf{0 . 0 1 7})$ & $-0.49 \pm 0.33(0.140)$ \\
\hline
\end{tabular}

Fig. 3 Use of substrates for sleeping by Psammophilus dorsalis lizards in $\mathbf{a}$ urban and $\mathbf{b}$ rural sites
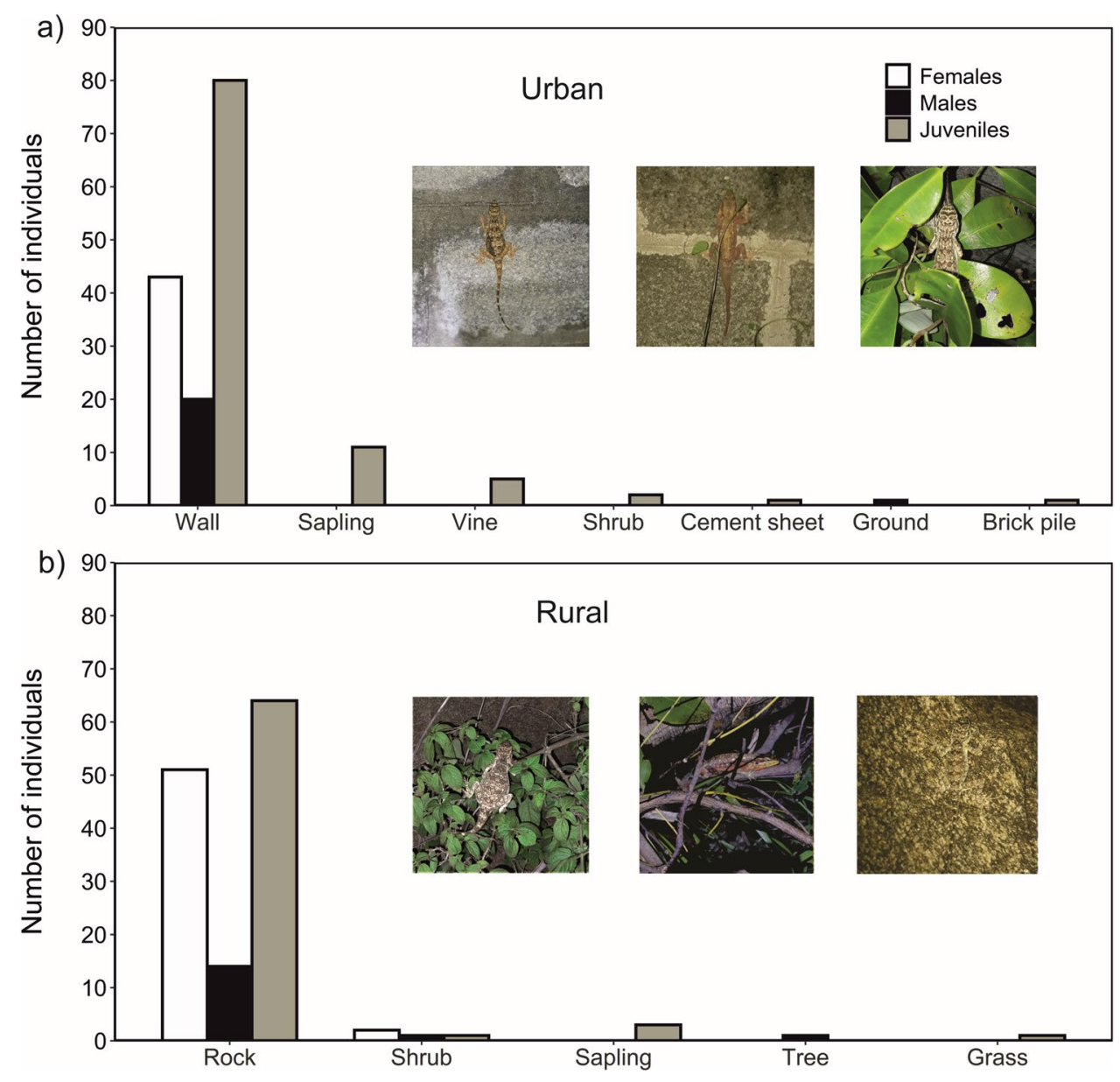

\section{Light conditions}

Lizards used sleep sites that were "covered" (urban lizards $=44$ vs rural lizards $=9$ ), "exposed" (urban $=98$ vs rural $=115$ ), and "inside" (urban $=4$ vs rural $=5$ ). Sleep sites of urban lizards had a higher likelihood of being "covered" as compared to "exposed" (odds ratio $=9.27$,
95\% CI $=8.43-10.1$, Table 1). However, irrespective of population, males were more likely to sleep in "covered" sites (odds ratio $=3.36, p=0.006, \mathrm{CI}=2.49-4.22$ ) and "inside" crevices (odds ratio $=10.67, p=0.002$, $\mathrm{CI}=9.15-12.18$ ) compared to females (Online Resource 1 Table 2). Furthermore, sleep sites of adults were 
significantly more "covered" compared to those of juveniles (odds ratio $=0.07,95 \% \mathrm{CI}=-0.75$ to 0.9 ; Table 1 ).

Artificial illumination at sleep sites was significantly higher for urban lizards (mean \pm SE: $0.53 \pm 0.131 x$; range: 0 to $14.6 \mathrm{~lx}$; Table 1) compared to rural lizards ( $0 \mathrm{~lx})$, as well as for juveniles compared to adults (juveniles: $0.37 \pm 0.11 \mathrm{~lx}$; adults: $0.17 \pm 0.081 \mathrm{~lx}$ ). "Exposed" sleep sites had significantly higher illumination than "covered" sites $(\mathrm{W}=1632.5$, $p=0.014$; exposed: $0.65 \pm 0.18 \mathrm{~lx}$; covered: $0.47 \pm 0.25 \mathrm{~lx}$ ).

\section{Thermal characteristics}

Sleep sites in urban and rural areas did not differ significantly in perch temperature $(t=-0.29, p=0.77)$, substrate temperature $(t=-1.87, p=0.06)$, and environment temperature $(t=-1.85, p=0.07$; Fig. $2 \mathrm{c})$. Substrate temperature of "covered" vs "exposed" sites did not differ in either urban $(t=0.72, p=0.47)$ or rural areas $(t=1.43, p=0.21)$. Overall, lizard body temperatures were significantly lower than perch temperatures; perch temperatures were significantly higher than substrate temperatures, which in turn were significantly higher than available environment temperatures (Fig. 2; Online Resource 1 Table 3). This pattern was consistent across urban adults, urban juveniles, rural adults, and rural juveniles (Online Resource 1 Table 3). However, the mean temperature difference was small for body vs perch $\left(-0.30\right.$ to $\left.-0.72{ }^{\circ} \mathrm{C}\right)$, perch vs substrate $\left(0.13\right.$ to $\left.0.37{ }^{\circ} \mathrm{C}\right)$, and substrate vs environment $\left(0.80\right.$ to $\left.1.06{ }^{\circ} \mathrm{C}\right)$.

\section{Discussion}

Among the various changes to environments in urban areas, artificial light at night (ALAN), temperature, and the structure of the habitat and perches can alter where and how animals sleep. In this study, we find that Psammophilus dorsalis lizards in urban areas mitigate these challenges by displaying remarkable behavioral flexibility while still maintaining conserved choices in characteristics of their sleep sites. Their decisions to sleep in "covered" sites which reduce exposure to ALAN while still selecting sites with similar substrate types (i.e., rocky) and thermal properties illustrate solutions to urbanization. Our study is one of the first to comprehensively compare sleep behavior in rural and urban areas, by assessing structural, thermal, and light environments at sleep sites of lizards. We not only address knowledge gaps in sleep behavior response to urbanization (and particularly to ALAN; French et al. 2018) but fill a key gap in studies on urbanization by focusing on an urban reptile in Asia (Collins et al. 2021).

As per our prediction, we find strong support for behavioral flexibility in sleep site selection, as $P$. dorsalis was nine times more likely to use "covered" sleep sites in urban areas than in rural areas. Use of sheltered sites reduced the luminosity of the immediate environment for $P$. dorsalis during sleep, which is known to ameliorate the effects of ALAN (Raap et al. 2018b). The degree of ALAN avoidance varies across studies. Kolbe et al. (2021) found limited support for behavioral avoidance of short-term exposure to ALAN in Anolis lizards, despite the fact that experimental exposure to light resulted in a lower arousal threshold from sleep than dark conditions. Similarly, Ulgezen et al. (2019) found no avoidance of ALAN in Great tits Parus major, even when darker sites were available. Even though luminosity at specific sleep sites was relatively low in urban areas in our study, "dim" light intensities can still have negative consequences for sleep physiology and circadian rhythms (Brüning et al. 2015; Stenvers et al. 2016; Secondi et al. 2021; but see Borniger et al. 2013). Contrary to our expectations, we also observed a few lizards sleeping in sites illuminated with high light intensities (up to $14.6 \mathrm{~lx}$ ); therefore, avoidance of ALAN by this species is variable in the wild.

ALAN can also increase vulnerability to visually hunting predators (Kolbe et al. 2021). In our study areas, birds and dogs are known to attack $P$. dorsalis during the day, and although diurnal predation risk does not seem to differ between urban and rural populations (Balakrishna et al. 2021), domestic cats and dogs that free range in urban areas can still pose a threat to these lizards at night (Loyd et al. 2013). Therefore, predation risk may also explain the greater use of "covered" sites in the urban population compared to the rural population. We also found a greater proportion of males sleeping in "covered" sites or in crevices compared to females. Male P. dorsalis are larger than females and exhibit dynamic conspicuous coloration during the day, which increases their predation risk (Amdekar and Thaker 2019). These characteristics could make males more vulnerable to the potential ALAN-associated increase in predation risk, which they seem to actively ameliorate by sleeping unexposed. During our surveys of sleeping lizards, we did, however, find fewer males compared to females (Fig. 3). These uneven detections between the sexes could reflect the female-skewed sex ratio typically seen for $P$. dorsalis (Deodhar and Isvaran 2017) and/or the fact that males may be harder to find as they tend to sleep in more "covered" sites. Overall, the behavioral amelioration of ALAN by urban $P$. dorsalis, especially males, seems to suggest a strategy that reduces disturbance at the microhabitat scale. Whether $P$. dorsalis avoids ALAN at a landscape scale, by avoiding brighter parts of the city, remains to be determined.

Our observation that lizards use "covered" sleep sites could also be explained by other factors. The results could reflect a higher availability of "covered" sleep sites in urban areas; however, this seems unlikely given the ample vegetation cover (including Lantana camara) surrounding rocks in rural sites of the study. Behavioral flexibility to avoid 
ALAN-associated disturbance does not explain the use of covered sites in rural areas. It is possible that "covered" sites are also used in response to natural illumination (resulting from the interaction of cloud cover and moonlight; van Hasselt et al. 2021). Future research should examine sleep site selection in rural areas in response to the full breadth of natural illumination (e.g., on cloudless, full moon nights). "Covered" sites could accord other advantages, such as suitable thermal conditions; however, we did not find any differences in the substrate temperature of "covered" vs "exposed" sites in either urban or rural areas, indicating that thermal benefits are unlikely to drive the use of "covered" sites. We also cannot rule out the possibility that "covered" sites provide anti-predatory benefits to sleeping lizards, irrespective of urban or rural populations. Although immobility during sleep in itself is considered to provide safety from visually hunting predators (Meddis 1975), there is a lack of systematic assessments of predation pressure on nocturnally sleeping animals to determine whether "covered" sleep sites indeed reduce predation risk.

We also find support for urban lizards choosing sleep sites that conserve the structural conditions of rural sleep sites. Urban lizards predominantly used unpolished concrete block walls as sleep sites, which have high rugosity similar to rocks in rural habitats. Surface rugosity could be particularly important for sleeping $P$. dorsalis as the majority of these lizards sleep on vertical perches, irrespective of population (similar to Agama agama; Amadi et al. 2020). A vertical perch orientation could provide anti-predatory benefits by limiting the types of predators that could approach the sleeping lizard. Sleep sites are also known to be conserved in some other agamid lizards (e.g., Coryphophylax spp., Mohanty et al. 2016), even in response to habitat modification (Monilesaurus rouxii, Bors et al. 2020). The dependence of $P$. dorsalis on rough substrates as sleep sites might explain the lower perch height for lizard in urban areas, as perch sites are limited by the height of human-constructed walls in the urban study area. The predominant use of walls as sleep sites also explains the lower likelihood of horizontal and angular sleep perch orientations in urban areas (though the 95\% confidence interval spans zero). Perch orientation could have implications for sleep quality, but this relationship remains to be examined in reptiles (Mohanty et al. 2021). Furthermore, as compared to diurnal perch height (mean \pm SE for urban $=4.38 \pm 0.21 \mathrm{~m}$; rural $=5.91 \pm 0.57 \mathrm{~m}$; Batabyal et al. 2017), nocturnal perches of $P$. dorsalis are considerably lower $($ urban $=0.99 \pm 0.04 \mathrm{~m}$; rural $=1.21 \pm 0.06 \mathrm{~m})$. The lower sleep perch height in urban areas (ca. $20 \mathrm{~cm}$ less than rural populations), constrained by substrate availability, could thus make these lizards vulnerable to attacks by predators approaching from the ground (Bors et al. 2020). This vulnerable position could also adversely affect sleep quality (Tisdale et al. 2018). Our measurements of perch height at night, however, could have a bias against high perches, as detection is limited by the range of headlamps and lack of lizard movement, unlike daytime searches.

The thermal characteristics of sleep sites of $P$. dorsalis did not differ between urban and rural areas; and within populations, thermoregulatory conditions were similar. Regardless of population, we observe a consistent trend in that perch temperatures were higher than substrate temperatures, which in turn were higher than the surrounding environmental temperature. Despite the consistency, the effect sizes of these differences seem too small to be biologically relevant for $P$. dorsalis. Although some reptiles, particularly in temperate regions, are known to choose relatively warm sleep sites (Huey et al. 1989; Pereira et al. 2019), we did not find such a pattern for $P$. dorsalis in this season. Our findings also contrast observations of species, such as Agama agama lizards, that use artificial heat sources at night in urban areas (Amadi et al. 2020). The similarity of thermal environments between urban and rural sites that we record contradicts general expectations from the urban heat island effect caused by the anthropogenic modification of natural environments (Peng et al. 2012). Bengaluru's high vegetative cover and location on a plateau approximately $900 \mathrm{~m}$ above sea level keep the metropolitan areas relatively cool resulting in an almost "cool island effect" (Siddiqui et al. 2021). Lizards in these areas are thereby released from the typical thermal challenges of urbanization. Our study was also conducted in the post-breeding season when environmental temperatures are mild; it is possible that thermal preferences would be much more pronounced in the peak of summer (March-May) or in winter (November-February).

Additionally, we document several natural history information pertaining to the sleep behavior of $P$. dorsalis that were previously unrecorded. When using vegetation at night, $P$. dorsalis was found on thin unstable perches, which has been hypothesized to aid in early detection of approaching predators via tactile cues (Anderson 1998); similar use of thin perches is seen in several reptile taxa (reviewed in Mohanty et al. 2021). The suggested role of visual cues in aiding predator detection at night (Clark and Gillingham 1990; Mohanty et al. 2016), however, is not fully supported in the case of $P$. dorsalis, as sleeping lizards were positioned in all possible head directions as opposed to a predominantly "inward" direction that would enable visual detection of a predator approach. Our observation of some sleep aggregations contrasts with the generally solitary behavior of the species during the active phase. Similar incidences of lizards sleeping in aggregations have been observed across reptiles and could provide anti-predatory and thermal benefits (Amadi et al. 2020; reviewed in Mohanty et al. 2021). Aggregations at night could also provide social benefits as territories of females overlap with those of males (Deodhar and Isvaran 
2018). Finally, observations of male coloration during the sleeping phase revealed a wide gradient corresponding to known color patterns associated with courtship, competition (or stress), and neutral conditions during the active phase (Batabyal and Thaker 2017b); this raises interesting questions on the mechanisms and costs-benefits of color during sleep (reviewed in Mohanty et al. 2021).

Although our study provides evidence for flexible sleep response to urbanization, it is limited to only one sleep trait, i.e., sleep site selection. The mechanism underlying the behavioral shift to sleeping in covered sites by urban lizards remains to be examined. Urban and rural populations of $P$. dorsalis show morphological differences in body size and limb morphometrics (Balakrishna et al. 2021), which could have arisen from micro-evolutionary differences between the populations. Our findings for sleep behavior points to behavioral plasticity rather than genetic adaptation as the potential mechanism. Electrophysiological markers of sleep, such as electro-encephalogram and electrooculogram which provide robust, quantitative measures of sleep, can further elucidate responses to urbanization (Aulsebrook et al. 2016, 2021). Recent advances in sleep logger miniaturization have made such electrophysiological recordings possible in the wild for even relatively small organisms (e.g., lizards; Massot et al. 2019). Studies using miniature sleep loggers that include measurements of the light conditions (Dominoni et al. 2014) would provide interesting insights on sleep duration, fragmentation, and timing (Lima et al. 2005) of urban populations of reptiles. Apart from light pollution (static and transient), how sound and vibration generated in urban environments affect sleep is an underexplored research direction (Nordt and Klenke 2013). Many studies have documented higher stress in urban populations (e.g., Amdekar et al. 2018), but the role of hormones (e.g., timing and concentration of melatonin or corticosterone) in shaping ecophysiological responses of sleep to urbanization must also be evaluated. Studying the ecology of sleep under global change processes holds substantial research potential.

Supplementary Information The online version contains supplementary material available at https://doi.org/10.1007/s00265-021-03101-5.

\begin{abstract}
Acknowledgements The thermal image camera was acquired with a DST-FIST grant to the Center for Ecological Sciences. We would like to thank Adhith Swaminathan, Alissa Barnes, Anwesha Naskar, Avik Banerjee, Caleb Daniel, Chetan Rao, Dhanya Bharath, Gauri Gharpure, Pritha Dey, Shawn Dsouza, Subhasmita Patro, Tanmay Wagh, and Udita Bansal for help with fieldwork. We thank two anonymous reviewers for their valuable inputs to the manuscript.
\end{abstract}

Author contribution NPM and MT contributed to study conceptualization and design. Field work was carried out by NPM and MJ. Data analysis was performed by NPM with inputs from MT. The first draft of the manuscript was written by NPM, and all authors contributed to editing the manuscript. All authors read and approved the final manuscript.

Funding This research was funded by the Indian Institute of Science's Raman Post-doctoral Fellowship (to NPM), and the DBT-IISc partnership program.

Data availability The dataset generated and/or analyzed for the study has been made available as Online Resource 2.

\section{Declarations}

Ethics approval Ethics approval for the study was granted by the Institutional Animal Ethics Committee, Indian Institute of Science (\# CAF/ Ethics/739/2020). All applicable international, national, and institutional guidelines for the use of animals were followed.

Conflict of interest The authors declare no competing interests.

\section{References}

Amadi N, Belema R, Chukwu HO, Dendi D, Chidinma A, Meek R, Luiselli L (2020) Life in the suburbs: artificial heat source selection for nocturnal thermoregulation in a diurnally active tropical lizard. Web Ecol 20:161-172

Amdekar MS, Kakkar A, Thaker M (2018) Measures of health provide insights into the coping strategies of urban lizards. Front Ecol Evol 6:128

Anderson JR (1984) Ethology and ecology of sleep in monkeys and apes. Adv Stud Behav 14:165-229

Anderson JR (1998) Sleep, sleeping sites, and sleep-related activities: awakening to their significance. Am J Primatol 46:63-75

Arnfield AJ (2003) Two decades of urban climate research: a review of turbulence, exchanges of energy and water, and the urban heat island. Int J Climatol 23:1-26

Aulsebrook AE, Connelly F, Johnsson RD, Jones TM, Mulder RA, Hall ML, Vyssotski AL, Lesku JA (2020) White and amber light at night disrupt sleep physiology in birds. Curr Biol 30:1-7

Aulsebrook AE, Johnsson RD, Lesku JA (2021) Light, sleep and performance in diurnal birds. Clocks Sleep 3:115-131

Aulsebrook AE, Jones TM, Mulder RA, Lesku JA (2018) Impacts of artificial light at night on sleep: a review and prospectus. J Exp Zool A Ecol Integr Physiol 329:409-418

Aulsebrook AE, Jones TM, Rattenborg NC, Roth TC II, Lesku JA (2016) Sleep ecophysiology: integrating neuroscience and ecology. Trends Ecol Evol 31:590-599

Balakrishna S, Amdekar MS, Thaker M (2021) Morphological divergence, tail loss, and predation risk in urban lizards. Urban Ecosyst 24:1391-1398

Batabyal A, Balakrishna S, Thaker M (2017) A multivariate approach to understanding shifts in escape strategies of urban lizards. Behav Ecol Sociobiol 71:83

Batabyal A, Thaker M (2017) Signalling with physiological colours: high contrast for courtship but speed for competition. Anim Behav 129:229-236

Batabyal A, Thaker M (2019a) Lizards from suburban areas learn faster to stay safe. Biol Lett 15:20190009

Batabyal A, Thaker M (2019b) Social coping styles of lizards are reactive and not proactive in urban areas. Gen Comp Endocrinol 270:67-74

Bennie J, Davies TW, Cruse D, Gaston KJ (2016) Ecological effects of artificial light at night on wild plants. J Ecol 104:611-620 
Borniger JC, Weil ZM, Zhang N, Nelson RJ (2013) Dim light at night does not disrupt timing or quality of sleep in mice. Chronobiol Int 30:1016-1023

Bors M, Mohanty NP, Shankar PG (2020) Anti-predatory sleep strategies are conserved in the agamid lizard Monilesaurus rouxii. Behav Ecol Sociobiol 74:121

Bradsworth N, White JG, Rendall AR, Carter N, Cooke R (2021) Where to sleep in the city? How urbanisation impacts roosting habitat availability for an apex predator. Global Ecol Conserv 26:e 01494

Brüning A, Hölker F, Franke S, Preuer T, Kloas W (2015) Spotlight on fish: light pollution affects circadian rhythms of European perch but does not cause stress. Sci Total Environ 511:516-522

Clark DL, Gillingham JC (1990) Sleep-site fidelity in two Puerto Riean lizards. Anim Behav 39:1138-1148

Collins MK, Magle SB, Gallo T (2021) Global trends in urban wildlife ecology and conservation. Biol Conserv 261:109236

Deodhar S, Isvaran K (2017) Breeding phenology of Psammophilus dorsalis: patterns in time, space and morphology. Curr Sci 10:2120-2126

Deodhar S, Isvaran K (2018) Why do males use multiple signals? Insights from measuring wild male behavior over lifespans. Front Ecol Evol 6:75

Dominoni DM, Carmona-Wagner EO, Hofmann M, Kranstauber B, Partecke J (2014) Individual-based measurements of light intensity provide new insights into the effects of artificial light at night on daily rhythms of urban-dwelling songbirds. J Anim Ecol 83:681-692

Downs CT, Awuah A, Jordaan M, Magagula L, Mkhize T, Paine C, Raymond-Bourret E, Hart LA (2015) Too hot to sleep? Sleep behaviour and surface body temperature of Wahlberg's Epauletted Fruit Bat. PLoS ONE 10:e119419

Eban-Rothschild A, Giardino WJ, de Lecea L (2017) To sleep or not to sleep: neuronal and ecological insights. Curr Opin Neurobiol 44:132-138

Fischer JD, Cleeton SH, Lyons TP, Miller JR (2012) Urbanization and the predation paradox: the role of trophic dynamics in structuring vertebrate communities. Bioscience 62:809-818

French SS, Webb AC, Hudson SB, Virgin EE (2018) Town and country reptiles: a review of reptilian responses to urbanization. Integr Comp Biol 58:948-966

Goller M, Goller F, French SS (2014) A heterogeneous thermal environment enables remarkable behavioral thermoregulation in Uta stansburiana. Ecol Evol 4:3319-3329

Huey RB, Peterson CR, Arnold SJ, Porter WP (1989) Hot rocks and not-so-hot rocks: retreat-site selection by Garter Snakes and its thermal consequences. Ecology 70:931-944

Imeri L, Opp MR (2009) How (and why) the immune system makes us sleep. Nat Rev Neurosci 10:199-210

Kolbe JJ, Moniz HA, Lapiedra O, Thawley CJ (2021) Bright lights, big city: an experimental assessment of short-term behavioral and performance effects of artificial light at night on Anolis lizards. Urban Ecosyst (published online, https://doi.org/10.1007/ s11252-021-01098-3)

Lardner B, Yackel Adams AA, Knox AJ, Savidge JA, Reed RN (2019) Do observer fatigue and taxon bias compromise visual encounter surveys for small vertebrates? Wildlife Res 46:127-135

Lima SL, Rattenborg NC, Lesku JA, Amlaner CJ (2005) Sleeping under the risk of predation. Anim Behav 70:723-736

Loyd KAT, Hernandez SM, Carroll JP, Abernathy KJ, Marshall GJ (2013) Quantifying free-roaming domestic cat predation using animal-borne video cameras. Biol Conserv 160:183-189

Massot B, Arthaud S, Barrillot B, Roux J, Ungurean G, Luppi P-H, Rattenborg NC, Libourel P-A (2019) ONEIROS, a new miniature standalone device for recording sleep electrophysiology, physiology, temperatures and behavior in the lab and field. J Neurosci Methods 316:103-116

Meddis R (1975) On the function of sleep. Anim Behav 23:676-691

Mohanty NP, Harikrishnan S, Vasudevan K (2016) Watch out where you sleep: nocturnal sleeping behaviour of Bay Island lizards. PeerJ 4:e1856

Mohanty NP, Wagener C, Herrel A, Thaker M (2021) The ecology of sleep in non-avian reptiles. Biol Rev (published online, https:// doi.org/10.1111/brv.12808)

Nordt A, Klenke R (2013) Sleepless in town-drivers of the temporal shift in dawn song in urban European blackbirds. PLoS ONE 8:e71476

Ouyang JQ, de Jong M, van Grunsven RHA, Matson KD, Haussmann MF, Meerlo P, Visser ME, Spoelstra K (2017) Restless roosts: light pollution affects behavior, sleep, and physiology in a freeliving songbird. Glob Change Biol 23:4987-4994

Peng S, Piao S, Ciais P, Friedlingstein P, Ottle C, Bréon FM, Nan H, Zhou L, Myneni RB (2012) Surface urban heat island across 419 global big cities. Environ Sci Technol 46:696-703

Pereira JJ, Lopes EP, Carretero MÁ, Vasconcelos R (2019) Insular geckos provide experimental evidence on refuge selection priorities by ectotherms. Behav Process 164:260-267

Piéron H (1912) Le problème physiologique du sommeil. Masson, Paris

R Core Team (2021) R: a language and environment for statistical computing. R Foundation for Statistical Computing, Vienna, Austria, http://www.R-project.org

Raap T, Pinxten R, Eens M (2015) Light pollution disrupts sleep in free-living animals. Sci Rep 5:13557

Raap T, Pinxten R, Eens M (2018a) Cavities shield birds from effects of artificial light at night on sleep. J Exp Zool A Ecol Integr Physiol 329:449-456

Raap T, Thys B, Grunst AS, Grunst ML, Pinxten R, Eens M (2018b) Personality and artificial light at night in a semi-urban songbird population: no evidence for personality-dependent sampling bias, avoidance or disruptive effects on sleep behaviour. Environ Pollut 243:1317-1324

Radder RS, Saidapur SK, Shanbhag BA (2005) Population density, microhabitat use and activity pattern of the Indian rock lizard, Psammophilus dorsalis (Agamidae). Curr Sci 89:560-566

Radder RS, Saidapur SK, Shine R, Shanbhag BA (2006) The language of lizards: interpreting the function of visual displays of the Indian rock lizard, Psammophilus dorsalis (Agamidae). J Ethol 24:275-283

Schmidt MH (2014) The energy allocation function of sleep: a unifying theory of sleep, torpor, and continuous wakefulness. Neurosci Biobehav Rev 47:122-153

Secondi J, Mondy N, Gippet JMW, Touzot M, Gardette V, Guillard L, Lengagne T (2021) Artificial light at night alters activity, body mass, and corticosterone level in a tropical anuran. Behav Ecol 32:932-940

Siddiqui A, Kushwaha G, Raoof A, Verma PA, Kant Y (2021) Bangalore: urban heating or urban cooling? Egypt J Remote Sensing Space Sci 24:265-272

Stenvers DJ, van Dorp R, Foppen E, Mendoza J, Opperhuizen AL, Fliers E, Bisschop PH, Meijer JH, Kalsbeek A, Deboer T (2016) Dim light at night disturbs the daily sleep-wake cycle in the rat. Sci Rep 6:35662

Sun J, Raap T, Pinxten R, Eens M (2017) Artificial light at night affects sleep behaviour differently in two closely related songbird species. Environ Pollut 231:882-889

Tisdale RK, Lesku JA, Beckers GJL, Vyssotski AL, Rattenborg NC (2018) The low-down on sleeping down low: pigeons shift to lighter forms of sleep when sleeping near the ground. J Exp Biol 221:jeb182634 
Ulgezen ZN, Käpylä T, Meerlo P, Spoelstra K, Visser ME, Dominoni DM (2019) The preference and costs of sleeping under light at night in forest and urban great tits. Proc R Soc B 286:20190872

van Hasselt SJ, Hut RA, Allocca G, Vyssotski AL, Piersma T, Rattenborg NC, Meerlo P (2021) Cloud cover amplifies the sleepsuppressing effect of artificial light at night in geese. Environ Pollut 273:116444

Vasconcelos R, Santos X, Carretero MA (2012) High temperatures constrain microhabitat selection and activity patterns of the insular Cape Verde wall gecko. J Arid Environ 81:18-25
Warren PS, Katti M, Ermann M, Brazel A (2006) Urban bioacoustics: it's not just noise. Anim Behav 71:491-502

Publisher's note Springer Nature remains neutral with regard to jurisdictional claims in published maps and institutional affiliations. 